\title{
Digital labour: An empty signifier?
}

\begin{abstract}
Since the early 2000s, the expression 'digital labour' has identified an influential theoretical proposition in the Marxist critique of the political economy of digital media, which sees the leisure-driven, unpaid activities of social media users as unremunerated forms of work contributing to Internet companies' profits. Over the years, however, this expression has evolved into an umbrella term, used to describe a variety of practices and instances concerning the broader relationship between labour and digital technology - including paid work - often with little or no relation to the original theory. Reflecting on this evolution, this article argues that 'digital labour' has become a kind of empty signifier, unable to serve a clearly distinguishable critical or analytical purpose. Focusing on the emergence of platform labour, it shows how 'digital' and 'labour' have come to be largely inseparable dimensions and discusses the related implications.
\end{abstract}

Keywords: audience labour, digital labour, digital economy, gig economy, platform labour

\section{Introduction}

Since the early 2000s, the expression 'digital labour' has identified an influential theoretical proposition that builds on the Marxist tradition to devise a critique of the emergent digital economy (Fuchs, 2014, 2010; Fuchs and Sevignani, 2013; Scholz, 2012; Dyer-Witheford, 2010). In its original formulation, this represents an almost literal application of Marx's labour theory of value to the digital domain, aimed at accounting for the appropriation of the leisureoriented, unpaid activities of users by Internet companies, otherwise described in less critical terms as forms of 'prosumption' (Ritzer and Jurgenson, 2010) or 'produsage' (Bruns, 2007). From this perspective, 'digital labour' consists of unremunerated work that online users undertake through their activity, which contributes to the profits of Internet companies and that henceforth should be compensated accordingly.

Over the years, however, the term 'digital labour' has come to be associated with a much wider set of phenomena that concern the broader relationships between labour and digital technology, thus increasingly delinking from the theoretical proposition outlined above. Research has labelled as forms of digital labour the unpaid activity of online users on social media platforms (e.g. Postigo, 2016) as well as the processes of datafication and profiling for purposes of advertising (Andrejevic, 2015; Manzerolle, 2010), but also the emergent forms of on-demand, paid work mediated (or enabled) by a digital platform, also called 'platform labour' (van Doorn, 2017) or the 'gig economy' (Graham and Woodcock, 2019). While these 
certainly entail some form of digital labour as originally intended, it appears as though the expression 'digital labour' has acquired some kind of genericity, becoming a sort of umbrella term that is increasingly delinked from its origins as a critical Marxist stance on labour and value.

In this article I take stock of this evolution and reflect on the implications deriving from it in the context of critical academic research on digital media. I argue that the expression 'digital labour' has become a kind of empty signifier that is no longer able to serve a clearly distinguishable critical or analytical purpose. This results in two related and equally problematic concerns. On the one hand, the popularization of the expression 'digital labour' as a generic term significantly weakens the critical dimension originally assigned to its Marxist position, irrespective of its (in fact, highly-contested) validity (see Kaplan, 2019; Rigi and Prey, 2016; Arvidsson and Colleoni, 2012; Fuchs, 2010). On the other hand, and perhaps most importantly, a blanket use of the expression 'digital labour' signals a new phase in the evolution of the relationship between labour and digital technology, whereby the two terms - digital and labour - are increasingly inseparable. This is epitomized by the diffusion of the digitally-mediated (or -enabled) forms of paid work that constitute platform labour. This incarnates a shift from the exploitation of unpaid, leisure-based user activity that is typical of social media - to the subordination of certain activities undertaken by users to a direct capital-labour relationship overseen by a digital platform, which entails new forms of control and surveillance. This ultimately overturns the conceptual premise of the Marxist notion of 'digital labour' as unpaid labour, as originally conceived.

In what follows, I first reconstruct the genealogy of the Marxist notion of 'digital labour' and discuss its somewhat controversial affirmation as an influential theoretical framework in critical media research (and beyond) as a derivative of the 'audience commodity' theory (Smythe, 1978). I then outline the trajectory that has resulted in the expression 'digital labour' becoming a generic description of phenomena that entail some kind of work activity and a digital component. Finally, building on existing research on platform labour and the gig economy, I draw a conceptual comparison between audience, digital and platform labour, to show how a digitally-mediated (or -enabled) capital-labour relationship can be observed in this new context. This will lead me to reflect, in conclusion, about the increasing impossibility of debating labour and digital technology as two separate components, and on the broader significance of this fact for critical academic scholarship on digital media.

\section{Digital labour: A contested framework}


Since the early 2000s, the expression 'digital labour' has referred to a specific theoretical proposition in critical media research, which identifies that:

the dominant capital accumulation model of contemporary corporate Internet platforms is based on the exploitation of users' unpaid labour, who engage in the creation of content and the use of blogs, social networking sites, wikis, microblogs, content sharing sites for fun and in these activities create value that is at the heart of profit generation (Fuchs and Sevignani, 2013: 237).

At a basic level, this represents an expansion of the seminal essay on 'free labour' by Tiziana Terranova (2000), which highlighted the unpaid, productive work undertaken by digital media users in exchange for their free access to online services (see also de Peuter and Dyer-Witheford, 2005; Kucklich, 2005; Hesmondhalgh, 2010). Conceived as such, the notion of 'digital labour' finds a key theoretical premise in the 'audience commodity' theory developed by Dallas Smythe (1977). This theory describes the compulsory viewing practice of commercials that television audiences are subjected to, which is argued to represent a form of unpaid work undertaken by viewers as they are exposed to advertising and marketing messages (see also Manzerolle, 2010; Rigi and Prey, 2015). Through the cognate notion of 'audience labour' (Fisher, 2012; Andrejevic, 2008), the audience commodity theory comes thus to be applied to the processes of commodification of social media user activity from the side of digital platforms for purposes of economic gain. This serves to raise a wideranging critique of the forms of exploitation of leisure-based, user-generated content production (Cote and Pybus, 2007), also termed 'playbour' (Kucklich, 2005, Scholz, 2012; Hesmondhalgh and Baker, 2013). It also serves as a critique of the processes of large-scale data gathering for purposes of advertising exposure contained within the business models of social media services such as Facebook or YouTube (Postigo, 2016; Andrejevic, 2015; Fisher, 2015).

Arguably one of the most prolific authors in this debate is Christian Fuchs (2014; 2012a; $2012 b ; 2010)$. Fuchs proposes a combination of the audience commodity theory with an 'orthodox' interpretation of the Marxist labour theory of value. He argues that social media users are made the object of a process of 'real subsumption' of their labour by Internet companies, which appropriate user activity for their own economic return, thereby transforming users into an imaginary class of exploited workers (see in particular Fuchs, 2014). A lively discussion has animated the scholarly community of critical media research around the relevance, and to some extent even the validity, of Fuchs's proposition. In a sharp critique, Arvidsson and Colleoni (2012) suggested that Fuchs's application of Marx's 
theory of value to Internet platforms (as articulated in Fuchs, 2010) is flawed. Value creation processes in the digital domain, they argue, actually delink from time-based quantification typical of the Marxist labour theory of value and instead revolve around the financial valorisation of affective exchanges, in a way that is akin to how brands behave on financial markets. Fuchs (2012a) responded directly to Arvidsson and Colleoni's (2012) critique, maintaining that his was the authentic Marxist interpretation of value theory and thus the only viable one (as reiterated in Fuchs, 2014). Other authors also weighed in on this dispute. Rigi and Prey (2015), for instance, highlight that Fuchs "mistakenly considers prosumers to be producers of a surplus value when it would be more accurate to see them as productive of a commons that is used to extract rent from advertisers" (2015: 403). However, they also criticise Arvidsson and Colleoni's emphasis on the role that affective relations play in value production processes - which, they argue, ultimately does not render Marx's labour theory of value totally irrelevant (Rigi and Prey, 2015: 393). Similarly, Comor (2015) underlines that both Fuchs and Arvidsson/Colleoni misinterpret Marx's value theory and questions the extent to which 'digital prosumption' represents a new value framework. The validity of the distinction between productive and unproductive labour in Fuchs's digital labour framework has also been questioned outside the critical media scholarship. In critical management research, for instance, Beverungen et al. (2015) suggest that Fuchs overstates the 'free labour' component in digital value creation processes, which they argue prevents an adequate acknowledgement of the forms of managerial organization of human activity that social media enforce to make users' work productive. Yet, in spite of the controversy surrounding it, this notion of digital labour quickly established itself as an important heuristic device in the broader critique of the exploitative dynamics that characterise the digital media industry as a whole.

It is not the purpose of this article to enter into this dispute. Nonetheless, I share Kaplan's (2019: 1) view that this debate has now reached something of an impasse: "No agreement has emerged among media theorists on even the most rudimentary questions, such as whether the activity on [social network sites] should count as work [...], whether this work counts as labour [...] or whether such labour is the ultimate source of industry profits". Over the years the expression 'digital labour' has come to be used indistinctly to identify almost all forms of direct or indirect labouring that takes place through the mediation of a digital medium, irrespective of their adherence to this theoretical construct. This, I contend, calls us to reassess its relevance. It is not by chance that this evolution has taken place alongside the emergence of what is now commonly referred to as 'platform labour' (van Doorn, 2017) or the 'gig economy' (Graham and Woodcock, 2019). 


\section{From digital labour to platform labour}

One of the most relevant phenomena in the recent developments of the digital economy is the diffusion of platforms that mediate the organization and execution of on-demand, paid work, such as Uber, Deliveroo, Amazon Mechanical Turk and Upwork. ${ }^{1}$ Research has labelled this context using the terms 'platform labour' (van Doorn, 2017) or a 'gig economy' (Graham and Woodcock, 2019). Existing empirical research on this topic portrays a lively phenomenon (see for instance Berg, 2016; Balaram et al., 2017). While precise figures are difficult to obtain, it is estimated that between $9 \%$ and $22 \%$ of workers in various European countries, such as the UK, Germany, Belgium, Switzerland and Italy, have engaged in platform-mediated (or -enabled) work in 2016-17 (Huws et al., 2018). ${ }^{2}$ Research suggests that digital 'gig work' is an appealing option particularly for those at the margins of the labour market, who can thus take advantage of the possibility to 'tap into' (The Economist, 2015) work opportunities with relative ease. Nonetheless, this has also quickly emerged as a remarkably exploitative form of work. The median income of platform workers is quite low, precarity is widespread and work is made of long hours and often physically dangerous activities, as epitomized by courier work (for a comprehensive overview see Graham and Woodcock, 2019).

When researchers began to take notice of the diffusion of platform-mediated (or -enabled) work practices, many turned to using the expression 'digital labour' to describe them, as a generic reference for exploitative forms of digital-related activity. What's more, this genericity did not just apply to platform labour: in the edited collection curated by Scholz (2012), for instance, a variety of phenomena fall under the digital labour umbrella, including hacking (Wark, 2012), creative labour (Ross, 2012), and on-demand 'click-work' undertaken on Amazon's Mechanical Turk (Aytes, 2012). Similarly, Cardon and Casilli (2015) use the expression 'digital labour' in a generic way, describing it as "the reduction of our 'digital relationships' to a phase of the production process, the subsumption of the social under the merchant in the context of our technological usages" (Cardon \& Casilli 2015: 13) - a definition that manages at once to include what they define as on-demand work platforms (e.g. Uber and TaskRabbit), microwork platforms (e.g. Amazon's Mechanical Turk), social network sites, and even connected objects in the Internet of Things. Casilli's stance is principled on the presence of four features that determine an example of 'digital labour': among these, the performance of 'certain unpaid tasks' by users is only one aspect of a more complex framework that entails the compliance of users to an actual work contract; a datafied and gamified performance measurement; and a fake self-employment relationship what Casilli calls 'technological parasubordination' (2016: 16). An analogous application can be found in the classification of 'crowdwork' offered by Howcroft and Bergvall-Kareborn 
(2018). Their typology places 'playbour crowdwork' (essentially Fuchs' digital labour, see Howcroft and Bergvall-Kareborn, 2018: 7) alongside 'online task crowdwork' (e.g.

Mechanical Turk); asset-based services (e.g. Uber), and 'profession-based crowdwork' (online freelancing), all in the same context (a similar approach can be found in Kenney and Zysman, 2019). Indeed, looking at practices of outsourcing on online labour markets in disadvantaged parts of the world, Graham et al. (2017) call 'digital labour' those "paid activities undertaken through digital labour markets" (2017: 3, see also Wood et al., 2019). Fuchs himself (Fuchs and Sandoval, 2014) seems to suggest all forms of labour involved in the production, circulation and use of digital media - such as online work, cyber work, virtual work and other similar terms - should be reconciled under his digital labour framework in one 'digital labour theory of value' (see also Fuchs, 2012b).

As this brief review demonstrates, in coincidence with the emergence of platform labour the expression 'digital labour' has shifted in meaning, being increasingly used in a way that is largely devoid of its original conceptual premises and becoming a generic expression that indicates the presence of a digital component in a context of work (or a work-related activity). This genericity, I contend, has significantly weakened the critical dimension that originally belonged to the concept as it comes from the Marxist tradition, notwithstanding its highly contested nature. While for some a reference to 'digital labour' describes the exploitation of unpaid user activity and personal data for value creation purposes, for others it simply represents a term that indicates some kind of role played by digital technologies in mediating, enabling or organizing the execution of work activities, perhaps with an exploitative nuance.

This genericity also impedes the ability to adequately appreciate the qualitative shift that has taken place in the relationship between labour and digital technology in recent years, and which is epitomized by platform labour. As contributions by Graham et al. (2017) and Wood et al. (2019) in particular suggest, there seems to be a mismatch between the conceptual premises of the Marxist notion of digital labour as unpaid work, and emergent platformmediated (or -enabled) forms of paid work. Digital work platforms, in other words, represent a qualitative shift away from the notion of audience commodification and exploitation of the unpaid, leisure-based activity of users that represents the basis of the digital labour proposition à la Fuchs. Different from social media such as Facebook or YouTube, which are advertising-based platforms, the key purpose of 'lean' platforms such as Uber and Deliveroo (Srnicek, 2016) is to directly oversee the exchange of labour as a commodity between consumers/clients and users/workers who undertake paid, 'real' work activities on an ondemand basis (see Graham and Woodcock, 2019). Conceived as such, platform labour 
constitutes a subversion of the theoretical standpoint from which the digital labour construct originates (see also Fish and Srinivasan, 2012). While from a purely descriptive perspective instances of platform labour arguably entail the appropriation of certain unpaid user activity and personal user data for profit-making purposes, ultimately the key feature of platform labour does not lie in the exploitation of users' free labour but in the presence of a digital platform that imposes a capital-labour relationship upon users, facilitating - and regulating the direct exchange of labour as a commodity.

\section{The specificity of platform labour}

While it is true, strictu sensu, that digital work platforms are first and foremost media infrastructures (Gillespie, 2010), following Srnicek (2016) I contend that digital work platforms cannot be treated - empirically and theoretically - like any other social media platform. On the contrary, elaborating from Kushner (2013: 1248), these platforms must be considered as a new kind of organizational actor, which replaces the role once held by old intermediaries (most commonly, agencies) who would usually connect workers to hirers. Thus, taken as media infrastructures the specificity of digital work platforms lies in their capacity to re-mediate and datafy the meeting of supply and demand of work (van Doorn, 2017), to the ultimate aim of subjecting the social relations of production involved in the direct exchange of labour as a commodity to a traditional capital-labour relation (author removed), and to forms of algorithmic-driven organization, control and surveillance (Moore, 2017; Rosenblat and Stark, 2016).

\section{[INSERT TABLE 1 ABOUT HERE]}

The comparison of some of the key features of audience, digital and platform labour to appraise the distinctive aspects of the latter (Table 1), shows that in platform labour:

1) the subjects involved are not viewers or users whose leisure activity is exploited but actual workers who willingly subject themselves to the execution of activities commissioned by a customer/client through a digital platform, which effectively acts as a 'shadow' or 'pseudo' employer (Friedman, 2014);

2) the labouring activity does not consist of the leisure-driven consumption of a certain medium, or the unpaid production of content that is then shared on social media, but in a clearly-designed and agreed-upon task - the 'gig' - executed in exchange for formal monetary remuneration;

3) the form of exploitation shifts from the 'consumption work' of audiences and the datafication of the 'productive leisure' of social media users to a context whereby 
algorithms: a) regulate the organization and execution of pre-determined, paid work activities; b) determine the value of such work through opaque calculations; and c) use 'productive metrics' (Beer, 2016), particularly reputation scores, as tools of control and surveillance (Moore, 2017; Rosenblat and Stark, 2016);

4) the medium involved shifts from content-based media such as television or social media to contentless digital platforms whose main purpose is to directly mediate the exchange of labour as a commodity between two parties.

As a result, if we consider digital work platforms primarily as digital media infrastructures that is, at a basic level, mediators of social relations - it may be argued that, instead of audiences, their mediation actually 'produces' supply and demand of work as peculiar digital aggregations. I propose calling these 'labour publics'. These should be conceived as a variation of Gabriel Tarde's (1989 [1901]) notion of publics as the modern form of organization par excellance. However, these should not be intended in the classical meaning of aggregations of people who engage in public discussion (Butsch, 2011), underpinned by the notion of public sphere. Rather, a 'public' here should be seen in interactional terms as a counterpart to the notion of community: while communitarian interaction is characterised by deep social bonds and a dimension of value sharing, the Tardian notion of publics identifies forms of ephemeral and interest-driven sociality (see Caliandro, 2018; Arvidsson, 2013; Wittel, 2001). For Tarde, publics are groups of social actors who are 'strangers' to each another, are united by a momentary shared interest, and then disband once this is concluded. Analogously, it may be said that digital work platforms produce supply and demand of work as groups of social actors made of 'quasi-strangers' who engage in ephemeral and interest-driven social exchanges, constituted by a temporary bond on the basis of a shared interest - the successful completion of the task or 'gig' - which actually dissolves once this is completed. (On Uber, for instance, a customer cannot choose with whom to ride next, or to ride with the same driver on another occasion). In turn, these ephemeral social exchanges are foundational to the success of the transactional exchange of labour as a commodity and its valorisation. Digital work platforms re-mediate and datafy the social relations that constitute the encounter between supply and demand of work, transforming these social relations into algorithmically-regulated and coordinated, temporary relations of production that are exclusive to the context in which they originate.

\section{Conclusion}

To some degree, this evolution of the term 'digital labour' may be seen as an inevitable byproduct of the popularity that the Marxist theory of digital labour has achieved in academic circles (and beyond), as it gained long-lasting influence and strong critique in equal amounts. 
Yet, despite calling the term 'digital labour' an empty signifier, I actually do not call for the dismissal of the Marxist theory of digital labour as a theoretical proposition. In fact, I believe it continues to be an extremely valuable resource in the critique of the forms of exploitation of online activity that are typical of the social media industry, as well as of the distortions that underpin datafication practices, as vividly demonstrated by the Cambridge Analytica scandal (Cadwalladr, 2018). It is this debate, among other things, that has created the conditions for Zuboff's (2019) comprehensive indictment of tech companies such as Google and Facebook as the harbingers of a new age of 'surveillance capitalism'.

However, this generic evolution of the expression 'digital labour' has wider implications for the study of work in digital capitalism, and specific ones for critical media research. If the term 'digital labour' originally stood as another term for unpaid, exploitative, value-generating digital-based activity (Fuchs, 2014), over time the scope of what is 'digital labour' has substantially expanded, so that it is now almost impossible to untangle the 'digital' prefix from the 'labour' activity. Under the expression 'digital labour' today exists a heterogeneous set of practices, which consists of unpaid and paid work, digitally-mediated and digital-based 'gig work', but also domestic labour, cognitive and creative labour, and much more - to the extent that the specificity originally characterizing the Marxist theory of 'digital labour' has been lost. It is in this sense that I argue the expression 'digital labour' has become an empty signifier: today, the mere presence of some kind of digital technology playing a role in the labouring activities of individuals in a given context does not automatically coincide with the presence of unpaid work or exploitation (albeit it does in many cases, including 'gig work'). In short, the presence of a 'digital' component in labour today is nothing special; as a result, accounting for some kind of exploitative digital presence in a context of work is no longer sufficient to pursue the more ambitious objective of critiquing the relationship between capitalism, work and technology in the $21^{\text {st }}$ century. I use Jarrett's words (2018: np) here to maintain that:

(t)he key reason to present this critique [...] is to encourage future studies to move away from emphasising the novelty of immaterial [in this case, digital] labour and instead provide more nuanced and contextualised understandings of its relationship to capital, both in generalised overviews of the contemporary capitalist condition but also in studies of specific digital labour practices.

We need to look for these practices, moving beyond the mere diagnosis of a digital presence or role and instead illustrate the manifold ways in which the capital-labour relationship is enforced through them, if we want to produce a critique that remains relevant and timely. 
Relatedly, this also has specific implications for critical media research. This body of literature has suffered to some degree from an excessive attention to the platform as a media object, which has resulted in a limited focus on the platform as a social object. While research exists in this direction (e.g. Van Dijck et al., 2018), particularly in the context of cultural production (Nieborg and Poell, 2018; Duffy et al., 2019), the critical discussion on the relationship between digital platforms and work has had to confront the 'impasse' (Kaplan, 2019) around labour, value and social media exploitation inherited from the 'digital labour' debate. In turn, having to deal with a heavy load of theoretical implications, the 'digital labour' debate has been equally unable to make a clear distinction between Facebook, Twitter and YouTube, on the one hand, and the likes of Uber and Deliveroo on the other (albeit with exceptions, such as Srnicek, 2016). Instead, a closer look at the logics that are peculiar to digital work platforms, illustrated earlier, shows that the mediation of social relations they operate is becoming increasingly sophisticated, in a way that prevents the equating of these platforms with other social media. To adequately address this sophistication, critical media scholars need to ditch blanket generalizations and employ greater precision and clarity, theoretically and terminologically, as digital work platforms which, at their core, remain media infrastructures - become 'points of production' (author removed) and new organizers of labour in a growing number of contexts. This will allow us to expand our knowledge about platforms, their functioning and criticalities as media objects much further than our present understanding.

\section{Notes}

1. While often included in the context of platform labour and a 'gig economy', Airbnb is not considered in this paper as an example of 'gig work'. The intermediation exerted by this platform does not concern the direct purchase of labour, for example a cab ride, a delivery or a translation, but rather the sole renting of assets - a house or a room (see Schor, 2016).

2. Other estimates, however, account for a far less diffuse phenomenon. See for instance, in the US context, 'Contingent and Alternative Employment Arrangements Summary', Bureau of Labor Statistics, available at: https://www.bls.gov/news.release/conemp.nr0.htm (last access 8 June 2018).

\section{References}


Andrejevic, M. (2008). Watching television without pity: The productivity of online fans.

Television \& New Media, 9(1), 24-46.

Arvidsson, A. (2013). The potential of consumer publics. Ephemera, 13(2), 367.

Arvidsson, A., \& Colleoni, E. (2012). Value in Informational Capitalism and on the Internet. The Information Society, 28(3), 135-150.

Aytes, A. (2013). Return of the crowds. In T. Scholz (eds.), Digital Labor: The Internet as Playground and Factory, New York: Routledge, pp. 79-97.

Balaram, B., Warden, J. and Wallace-Stephens, F. (2017). Good Gigs: A fairer future for the UK's gig economy. London: RSA.

Beer, D. (2016). Metric Power. Basingstoke: Palgrave Macmillan.

Berg, J. (2016). Income security in the on-demand economy: Findings and policy lessons from a survey of crowdworkers. International Labour Organization, Conditions of Work and Employment Series, 74.

Beverungen, A., Böhm, S., \& Land, C. (2015). Free labour, social media, management: Challenging Marxist Organization Studies. Organization Studies, 36(4), 473-489.

Bruns, A. (2008). Blogs, Wikipedia, Second Life, and beyond: From production to produsage. Peter Lang.

Butsch, R. (2011). Audiences and publics, media and public spheres. In V.Nightinghale (eds.), The Handbook of Media Audiences, London: Routledge, 149-167.

Cadwalladr, C. (2018). “I Made Steve Bannon's Psychological Warfare Tool': Meet the Data War Whistleblower.' The Guardian, available at:

https://www.theguardian.com/news/2018/mar/17/data-war-whistleblower-christopher-wyliefaceook-nix-bannon-trump (last accessed 24 October 2019).

Caliandro, A. (2018). Digital methods for ethnography: Analytical concepts for ethnographers exploring social media environments. Journal of Contemporary Ethnography, 47(5), 551578. 
Cardon, D., \& Casilli, A. (2015). Qu'est-ce que le digital labor?. Paris: Ina.

Casilli, A. (2016). Is There a Global Digital Labor Culture?. 2nd symposium of the Project for Advanced Research in Global Communication (PARGC).

Comor, E. (2015). Revisiting Marx's value theory: A critical response to analyses of digital prosumption. The Information Society, 31(1), 13-19.

Coté, M., \& Pybus, J. (2007). Learning to immaterial labour 2.0: MySpace and social networks. Ephemera: Theory \& Politics in Organization, 7(1), 88-106.

De Peuter, G., \& Dyer-Witheford, N. (2005). A playful multitude? Mobilising and countermobilising immaterial game labour. Fibreculture, 5(1).

De Stefano, V. (2015). The rise of the just-in-time workforce: On-demand work, crowdwork, and labor protection in the gig-economy. Comparative Labour Law \& Policy Journal, 37, 471504.

Duffy, B. E., Poell, T., \& Nieborg, D. B. (2019). Platform Practices in the Cultural Industries: Creativity, Labor, and Citizenship. Social Media+ Society, 5(4), DOI: 2056305119879672.

Dyer-Witheford, N. (2010). Digital labour, species-becoming and the global worker. Ephemera: Theory \& Politics in Organization, 10(3), 484-503.

Fish, A., \& Srinivasan, R. (2012). Digital labor is the new killer app. New Media \& Society, 14(1), 137-152.

Fisher, E. (2015). Class struggles in the digital frontier: Audience labour theory and social media users. Information, Communication \& Society, 18(9), 1108-1122.

Fisher, E. (2012). How Less Alienation Creates More Exploitation? Audience Labour on Social Network Sites. tripleC: Communication, Capitalism \& Critique. Open Access Journal for a Global Sustainable Information Society, 10(2), 171-183.

Friedman G (2014) Workers without employers: Shadow corporations and the rise of the gig economy. Review of Keynesian Economics 2(2): 171-188. 
Fuchs, C. (2014). Digital Labour and Karl Marx. London: Routledge.

Fuchs, C. (2012a). With or Without Marx? With or Without Capitalism? A Rejoinder to Adam Arvidsson and Eleanor Colleoni. tripleC: Communication, Capitalism \& Critique. Open Access Journal for a Global Sustainable Information Society, 10(2), 633-645.

Fuchs, C. (2012b). Dallas Smythe Today-The Audience Commodity, the Digital Labour Debate, Marxist Political Economy and Critical Theory. Prolegomena to a Digital Labour Theory of Value. tripleC: Communication, Capitalism \& Critique. Open Access Journal for a Global Sustainable Information Society, 10(2), 692-740.

Fuchs, C. (2010). Labor in Informational Capitalism and on the Internet. The Information Society, 26(3), 179-196.

Fuchs, C., \& Sandoval, M. (2014). Digital workers of the world unite! A framework for critically theorising and analysing digital labour. tripleC: Open Access Journal for a Global Sustainable Information Society, 12(2), 486-563.

Gillespie, T. (2010). The politics of 'platforms'. New Media \& Society, 12(3), 347-364.

Graham, M., Hjorth, I. and Lehdonvirta, V. (2017). Digital labour and development: impacts of global digital labour platforms and the gig economy on worker livelihoods. Transfer: European Review of Labour and Research, DOI: 1024258916687250.

Graham, M., \& Woodcock, J. (2019). The gig economy: A critical introduction. London: Polity.

Heeks, R. (2017). Decent Work and the Digital Gig Economy: A Developing Country Perspective on Employment Impacts and Standards in Online Outsourcing, Crowdwork, etc. Global Development Institute. University of Manchester.

Hesmondhalgh, D. (2010). User-generated content, free labour and the cultural industries. Ephemera: Theory \& Politics in Organization, 10(3/4), 267-284.

Hesmondhalgh, D., \& Baker, S. (2013). Creative labour: Media work in three cultural industries. London: Routledge. 
Howcroft, D., \& Bergvall-Kåreborn, B. (2018). A Typology of Crowdwork Platforms. Work, Employment and Society, 0950017018760136.

Huws, U., Spencer, N., Syrdal, D., Holts, K. (2018) Work in the European Gig Economy. FEPS: Foundation for European Progressive Studies.

Jarrett, K. (2018). Laundering women's history: A feminist critique of the social factory. First Monday, 23(3).

Kaplan, M. (2019). The Self-consuming Commodity: Audiences, Users, and the Riddle of Digital Labor. Television \& New Media, DOI: 1527476418819002.

Kenney, M., \& Zysman, J. (2019). Work and Value Creation in the Platform Economy. In S. Vallas, A. Kovalainen (eds), Work and Labor in the Digital Age, Bingley: Emerald Publishing, pp. 13-41.

Kücklich, J. (2005). Precarious playbour: Modders and the digital games industry. Fibreculture, 5(1).

Kushner, S. (2013). The freelance translation machine: Algorithmic culture and the invisible industry. New Media \& Society, 15(8), 1241-1258.

Manzerolle, V. (2010). Mobilizing the audience commodity: Digital labour in a wireless world. Ephemera: Theory \& Politics in Organization, 10(4), 455.

Moore, P. (2017). The quantified self in precarity. Work, technology and what counts. London: Routledge.

Nieborg, D. B., \& Poell, T. (2018). The platformization of cultural production: Theorizing the contingent cultural commodity. New Media \& Society, 20(11), 4275-4292.

Postigo, H. (2016). The socio-technical architecture of digital labor: Converting play into YouTube money. New Media \& Society, 18(2), 332-349.

Rigi, J., \& Prey, R. (2015). Value, rent, and the political economy of social media. The Information Society, 31(5), 392-406. 
Ritzer, G., \& Jurgenson, N. (2010). Production, consumption, prosumption: The nature of capitalism in the age of the digital 'prosumer'. Journal of Consumer Culture, 10(1), 13-36.

Rosenblat, A. and Stark, L. (2016). Algorithmic Labor and Information Asymmetries: A Case Study of Uber's Drivers. International Journal of Communication, 10, 27.

Ross, A. (2012). In Search of the Lost Paycheck. In T. Scholz (eds.), Digital Labor: The Internet as Playground and Factory, New York: Routledge, pp. 13-32.

Scholz, T. (Ed.). (2012). Digital Labor: The Internet as Playground and Factory. New York: Routledge.

Schor, J. (2016). Debating the sharing economy. Journal of Self-Governance and Management Economics, 4(3), 7-22.

Smythe, D. W. (1977). Communications: blindspot of western Marxism. CTheory, 1(3), 1-27.

Srnicek, N. (2016). Platform capitalism. London: Wiley \& Sons.

Tarde, G. (1989 [1901]) L'opinion et la foule. Paris: Presses Universitaires de France.

Terranova, T. (2000). Free labor: Producing culture for the digital economy. Social text, 18(2), 33-58.

The Economist (2015) Workers on tap. Available at:

http://www.economist.com/news/leaders/21637393-rise-demand-economy-poses-difficultquestions-workers-companies-and (accessed 7 October 2019)

van Doorn, N. (2017). Platform labor: on the gendered and racialized exploitation of lowincome service work in the 'on-demand' economy. Information, Communication \& Society, 20(6), 898-914.

Van Dijck, J., Poell, T., \& De Waal, M. (2018). The platform society: Public values in a connective world. Oxford: Oxford University Press. 
Wark, M. (2013). Considerations on a Hacker manifesto. In T. Scholz (eds.), Digital Labor: The Internet as Playground and Factory, New York: Routledge, pp. 69-76.

Wittel, A. (2001). Toward a network sociality. Theory, Culture \& Society, 18(6), 51-76.

Wood, A., Graham, M., Lehdonvirta, V., Hjorth, I. (2019). Networked but Commodified: The (Dis) Embeddedness of Digital Labour in the Gig Economy." Sociology, DOI: 0038038519828906.

Zuboff, S. (2019). The age of surveillance capitalism: The fight for a human future at the new frontier of power. New York: Profile Books. 
Table. 1 - The specificity of 'platform labour'

\begin{tabular}{|c|c|c|c|}
\hline & $\begin{array}{l}\text { Audience Labour } \\
\text { (Smythe, 1977) }\end{array}$ & $\begin{array}{l}\text { Digital Labour } \\
\text { (Fuchs 2010, 2012, 2014) }\end{array}$ & Platform Labour \\
\hline Subjects & $\begin{array}{l}\text { Viewers, audience as } \\
\text { a commodity } \\
\text { (Smythe, 1977) }\end{array}$ & $\begin{array}{l}\text { Users as content } \\
\text { producers }\end{array}$ & Users as workers \\
\hline $\begin{array}{l}\text { Labouring } \\
\text { activity }\end{array}$ & Viewing & $\begin{array}{l}\text { Content production as } \\
\text { 'playbour' (Kuchlich, 2005; } \\
\text { Scholz, 2012) }\end{array}$ & Paid work \\
\hline $\begin{array}{l}\text { Form of } \\
\text { exploitation }\end{array}$ & $\begin{array}{l}\text { Audience } \\
\text { commodification }\end{array}$ & $\begin{array}{l}\text { 'Free labour' (Terranova, } \\
2000) \text {, datafication } \\
\text { (Andrejevic, 2008) }\end{array}$ & $\begin{array}{l}\text { 'Algorithmic } \\
\text { labour', } \\
\text { quantification } \\
\text { (Rosenblat and } \\
\text { Stark, 2016; } \\
\text { Moore, 2017), } \\
\text { productive metrics } \\
\text { (Beer, 2016) }\end{array}$ \\
\hline Medium & TV & $\begin{array}{l}\text { Content media (social } \\
\text { media) }\end{array}$ & $\begin{array}{l}\text { Contentless media } \\
\text { (digital work } \\
\text { platforms) }\end{array}$ \\
\hline
\end{tabular}

